\section{Applications of a Commercial Extract of the Brown Seaweed Ascophyllum nodosum Increases Drought Tolerance in Container-grown 'Hamlin' Sweet Orange Nursery Trees}

\author{
Timothy M. Spann ${ }^{1}$ \\ Horticultural Sciences Department, University of Florida, Institute of Food \\ and Agricultural Sciences, Citrus Research and Education Center, 700 \\ Experiment Station Road, Lake Alfred, FL 33850
}

\author{
Holly A. Little \\ Acadian Seaplants, 30 Brown Avenue, Dartmouth, Nova Scotia B3B1X8, \\ Canada
}

Additional index words. citrus sinensis, seaweed extract, deficit irrigation, drought stress, water use efficiency

\begin{abstract}
Hamlin' sweet orange trees on 'Carrizo' citrange and 'Swingle' citrumelo rootstocks were treated weekly with a commercial extract of the brown seaweed Ascophyllum nodosum at 5 and $10 \mathrm{~mL} \cdot \mathrm{L}^{-1}$ as either a soil drench or foliar spray. Half of the trees in each treatment were subjected to drought stress [irrigated at $50 \%$ of evapotranspiration (ET)], whereas the other half remained fully irrigated (100\% ET). Drought stress reduced shoot growth and leaf photosynthesis but increased root and total plant growth relative to the amount of water applied, thus increasing whole plant water use efficiency. Trees treated with seaweed extract and drought-stressed had significantly more total growth than untreated drought-stressed trees for both rootstocks. The maintenance of growth by the seaweed extract under drought stress conditions was unrelated to photosynthesis. However, the seaweed extract treatment did have a significant effect on plant water relations. Soil drench-treated trees had more growth and higher stem water potential than foliar-treated or control trees after 8 weeks of drought stress. These results indicate that seaweed extract may be a useful tool for improving drought stress tolerance of container-grown citrus trees.
\end{abstract}

Numerous physiological functions are affected by drought stress in citrus trees (GómezCadenas et al., 1996). Stomatal closure has been reported to occur within $2 \mathrm{~h}$ in response to severe drought stress in citrus (Tudela and Primo-Millo, 1992) and continuous stress may lead to reduced $\mathrm{CO}_{2}$ assimilation and inhibit growth (Brakke and Allen, 1995). However, Bradford and Hsiao (1982) concluded that restriction of canopy development was the most sensitive parameter to moderate drought stress. Thus, it is important to distinguish between moderate and severe drought stress when assessing physiological responses.

In Florida, citrus nursery trees are primarily produced in $2.65 \mathrm{~L}(10 \mathrm{~cm} \times 10 \mathrm{~cm} \times 34.3 \mathrm{~cm})$ containers commonly referred to as Citrapots (CPOT5H; Steuwe and Sons, Tangent, OR). As of Jan. 2007, all citrus propagation in Florida must occur in greenhouses that

Received for publication 1 Dec. 2010. Accepted for publication 18 Jan. 2011.

We thank Luis Pozo and Denny Cornelio for their technical assistance with treatment applications and data collection.

${ }^{1}$ To whom reprint requests should be addressed; e-mailspann@ufl.edu. meet specific state requirements for pest and disease exclusion (Florida Department of State, 2010). Most nurseries currently use overhead irrigation and as trees grow, the expanding leaf canopy reduces irrigation uniformity by blocking and deflecting water away from the roots. Uneven irrigation results in a portion of young trees receiving less water than optimal, resulting in uneven tree growth (Spann, unpublished data). Unless trees are rearranged on a bench, which is not a common practice, some trees experience relatively constant moderate drought stress under current production practices. Therefore, it is desirable to find ways of imduction uniformity.

Seaweed and seaweed extracts (SWE) have been used as soil amendments and fertilizers in agriculture for centuries, particularly in coastal temperate regions (Blunden and Gordon, 1986). The most commonly used species in agriculture belong to the brown seaweed family (Blunden and Gordon, 1986) and include the species Ascophyllum nodosum. SWEs are often classified as plant biostimulants (Khan et al., 2009) and are generally thought to contain trace amounts of macro- and micronutrient elements, amino acids, vitamins, cytokinins, auxins, abscisic acid-like compounds, and quaternary proving drought tolerance to improve pro- ammonium compounds (Crouch et al., 1992; Crouch and van Staden, 1993; Durand et al., 2003; Ördög et al., 2004; Reitz and Trumble, 1996; Stirk et al., 2003). However, some doubt has recently been shed on the actual levels of plant growth hormones in SWEs (Craigie, 2010).

Commercial extracts of $A$. nodosum have been reported to increase fruit yield and quality of citrus (Fornes et al., 1995, 2002; Koo, 1988; Koo and Mayo, 1994) and grapes (Norrie et al., 2002). Extracts from A. nodosum have also been reported to increase drought stress tolerance of grasses (Schmidt and Zhang, 1997; Zhang and Ervin, 2004) and vegetable and ornamental crops (Neily et al., 2010), but there are no published reports about their effects on drought stress tolerance in woody plants in general or citrus specifically.

The objective of this study was to determine if a commercially available alkaline extract of $A$. nodosum (Stimplex ${ }^{\circledR}$ Crop Biostimulant; Acadian Seaplants, Nova Scotia, Canada) improves drought stress tolerance and maintains shoot growth under drought conditions of sweet orange nursery trees grown on commonly used rootstocks.

\section{Materials and Methods}

Plant material. Forty-eight uniform 1-yearold nursery trees of 'Hamlin' sweet orange [Citrus sinensis (L.) Osbeck] grafted on 'Carrizo' citrange [Poncirus trifoliata (L.) Raf. $\times C$. sinensis $]$ and 'Swingle' citrumelo (P. trifoliata $\times C$. $\times$ paradisi Macfad.) rootstocks were obtained from a commercial citrus nursery. 'Carrizo' is classified as having good drought tolerance, whereas 'Swingle' is classified as having poor to intermediate drought tolerance (Castle et al., 2006). The trees were grown in standard 2.65-L Citra-pots with a peat-based soilless potting media according to standard nursery practices and were headed at $\approx 70 \mathrm{~cm} 6$ weeks before purchase to induce lateral branching. Experiments were conducted at the University of Florida's Citrus Research and Education Center (Lake Alfred, FL; long. $28.09^{\prime} \mathrm{N}$, lat. 81.73' W; elevation $51 \mathrm{~m}$ ) from Aug. to Oct. 2009. Trees were grown in an unshaded greenhouse with maximum photosynthetically active radiation at plant level of $1200 \mu \mathrm{mol} \cdot \mathrm{m}^{-2} \cdot \mathrm{s}^{-1}$ and natural photoperiods. Average day/night temperatures were $37 / 20^{\circ} \mathrm{C}$ and relative humidity varied diurnally from $40 \%$ to $100 \%$.

Seaweed extract and irrigation treatments. A $3 \times 2 \times 2$ factorial experiment (eight replicate trees per treatment) was designed with three treatments of SWE, two irrigation regimes, and two rootstocks. The experiment was conducted over a 12-week period. During the first 4 weeks, the trees were conditioned with weekly SWE applications under full irrigation. Starting with the fifth week and continuing through Week 12 , the trees were differentially irrigated as described subsequently. All irrigations included a dilute complete fertilizer solution at $75 \mathrm{mg} \mathrm{N} /$ L. During the drought stress period, the 50\% ET treatments were fertilized at $150 \mathrm{mg} \mathrm{N} / \mathrm{L}$ so that total fertilizer received was equivalent to that 
amount received under the $100 \%$ ET treatment. The complete fertilizer analysis was as follows: 7 nitrogen, $2 \mathrm{P}_{2} \mathrm{O}_{5}, 7 \mathrm{~K}_{2} \mathrm{O}, 0.1$ magnesium, 0.03 manganese, 0.01 copper, 0.02 zinc, 0.04 iron, and 0.01 boron (Growers Fertilizer Co., Inc., Lake Alfred, FL). SWE treatments were applied at $5 \mathrm{~mL} \cdot \mathrm{L}^{-1}$ as a soil drench or foliar spray once per week. Untreated trees served as controls. Foliar applications were applied to runoff, ensuring that upper and lower leaf surfaces were fully wetted. The soil surface was covered during application and until the product dried to prevent soil contamination. Drench applications were made in place of a standard irrigation and application volumes varied based on tree water use as described subsequently. At the end of the fourth week of treatment, before initiating drought stress treatments, all SWE-treated trees received a one-time application at 10 $\mathrm{mL} \cdot \mathrm{L}^{-1}$. SWE rates were returned to $5 \mathrm{~mL} \cdot \mathrm{L}^{-1}$ for all subsequent applications during the 8week drought stress period.

During the 4-week conditioning period, all trees were fully irrigated every 2 to $3 \mathrm{~d}$ as needed. Irrigation volumes were determined by weighing each pot at field capacity (after an irrigation and after allowing for free drainage to occur) and again just before irrigation. The weight loss per pot was assumed to equal total evapotranspirational water loss $(100 \%$ ET). These values were averaged for the 16 trees of each treatment for each rootstock and the trees were watered with a volume equivalent to the weight loss. Trees were reweighed and new irrigation volumes determined every 2 weeks to account for increases in weight resulting from growth. After the 4-week conditioning period, eight trees per SWE treatment per rootstock continued to be irrigated with $100 \%$ ET every 2 to $3 \mathrm{~d}$ as described previously. The other eight trees per treatment were irrigated at the same time interval but with $50 \%$ ET based on the water use of the $100 \%$ ET treatment. The goal was to maintain a relatively constant plant water status, either with or without drought stress, without large fluctuations between irrigation events.

During the drought stress period ( 8 weeks), the SWE concentration was doubled to 10 $\mathrm{mL} \cdot \mathrm{L}^{-1}$ for the drench-treated trees receiving $50 \%$ ET. Thus, they continued to receive the same total quantity of SWE as the $100 \%$ ET trees. Foliar applications continued to be made at $5 \mathrm{~mL} \cdot \mathrm{L}^{-1}$ regardless of irrigation treatment.

Data collection. The total shoot length (sum of all growing stems, including main trunk) was recorded weekly for all trees. Photosynthesis was measured immediately before and $24 \mathrm{~h}$ after an irrigation on clear sunny days during Weeks 4, 8, and 12 on six plants per treatment (same plants each time) using a single recently matured leaf per plant with a portable photosynthesis system (LI-6400XT; LI-COR Corp., Lincoln, NE) with a $6-\mathrm{cm}^{2}$ broadleaf chamber. The chamber was equipped with an external light-emitting diode light source (6400-02B; LI-COR Corp.) set to match the ambient light level on each measurement day. All measurements were made between 0900 and $1100 \mathrm{HR}$ to avoid high afternoon temperatures. During measurements, leaf temperature was $31 \pm 1.2{ }^{\circ} \mathrm{C}$ and leaf-to-air vapor pressure difference was $2.5 \pm 0.3 \mathrm{kPa}$ within the chamber.

Stem water potential $\left(\Psi_{\text {stem }}\right)$ was measured on all trees in each treatment immediately before and $24 \mathrm{~h}$ after irrigation during Weeks 8 and 12 using a pressure chamber (Soilmoisture Equipment Corp., Santa Barbara, CA; Scholander et al., 1965). One mature leaf per tree was selected per measurement and enclosed in a Mylar envelope for at least $1 \mathrm{~h}$ before measurement (McCutchan and Shackel, 1992). All measurements were made between 1100 and 1300 HR.

At the end of the study, all trees were destructively harvested; the stems and leaves were separated into new growth (developed during the 12-week experiment) and old growth (existing at the start of the experiment). New leaf area per tree, old leaf area per tree, new leaf dry weight, old leaf dry weight, new stem dry weight, old stem dry weight, and root dry weight were recorded. Before drying, total root length per tree was estimated using a lineintercept method (Tennant, 1975). Additionally, total water use efficiency (WUE) was calculated for each treatment on each rootstock by dividing total plant dry weight by the total volume of water applied over the 12 weeks.

Data analysis. Analysis of variance for a randomized complete block design was performed for the various parameters measured using Prism 5.0 (GraphPad Software, LaJolla, CA). Multiple mean comparisons were conducted across all drought and seaweed treatments by Tukey's honestly significant difference $(P=0.05)$. Percent data were arcsine trans- formed and analysis was performed on the transformed data.

\section{Results}

Rootstock main effects and interactions were not significant for any of the variables measured despite the different drought tolerance classification of the two rootstocks. However, for clarity of presentation, the data for the two rootstocks are shown independently.

All trees exhibited similar patterns of shoot growth during the course of the study (Fig. 1). Drought-stressed trees did not begin to exhibit slower growth rates until 2 weeks after the initiation of drought stress. By the end of the experiment, SWE-treated drought-stressed trees (drench and foliar application) on both rootstocks grew significantly more than untreated control trees. However, compared with fully irrigated control trees, drought-stressed trees grew less regardless of SWE treatment.

There was a significant interaction between drought stress and SWE treatment for new leaf area for each rootstock. Drought stress significantly reduced new leaf area on control trees of both rootstocks compared with fully irrigated trees (Fig. 2). For both rootstocks, SWEtreated drought-stressed trees had similar new leaf area per tree compared with SWE-treated fully irrigated trees. Where different, the drench treatment had more leaf area than the foliar treatment for both rootstocks.

For trees on 'Carrizo' rootstock, both SWE treatments maintained new leaf and new stem dry weight production under drought stress conditions (Figs. 3A and $\mathrm{C}$ ) relative to the

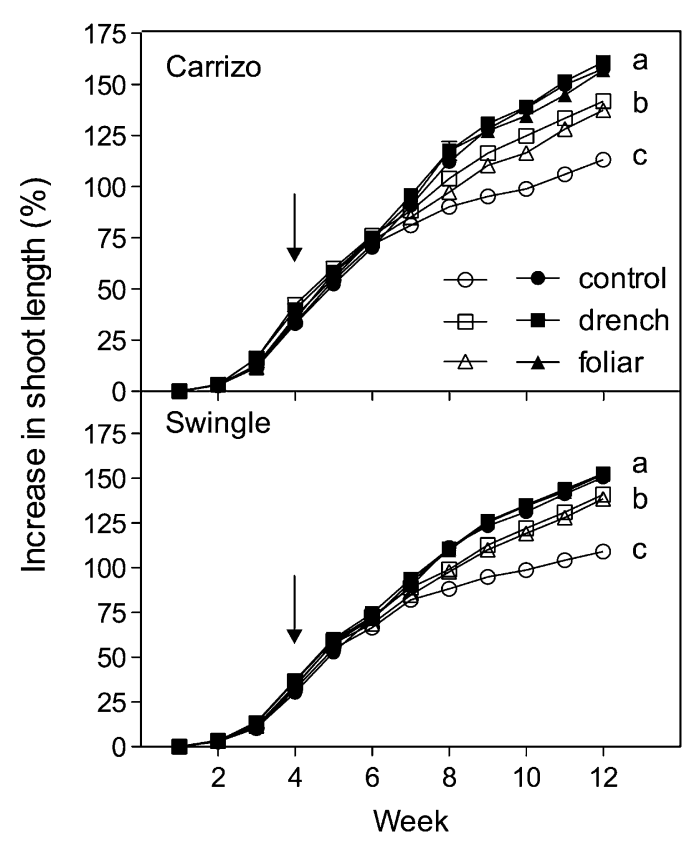

Fig. 1. Percent increase in shoot length for 'Hamlin' sweet orange trees grown on 'Carrizo' citrange (A) or 'Swingle' citrumelo (B) rootstocks for 12 weeks under well-watered conditions $(100 \%$ ET $=$ closed symbols) or drought stress $(50 \% \mathrm{ET}=$ open symbols $)$ and treated with seaweed extract as a soil drench or foliar spray compared with untreated control trees. The first 4 weeks of the study served as a conditioning period during which all trees were fully irrigated while receiving their respective seaweed extract treatments. Differential irrigation treatments began at the beginning of Week 5 (arrow) of the study. Lowercase letters indicate significant differences among treatment groupings at the end of the 12-week experiment (Tukey's honestly significant difference test, $P=0.05$ ). ET $=$ evapotranspiration. 


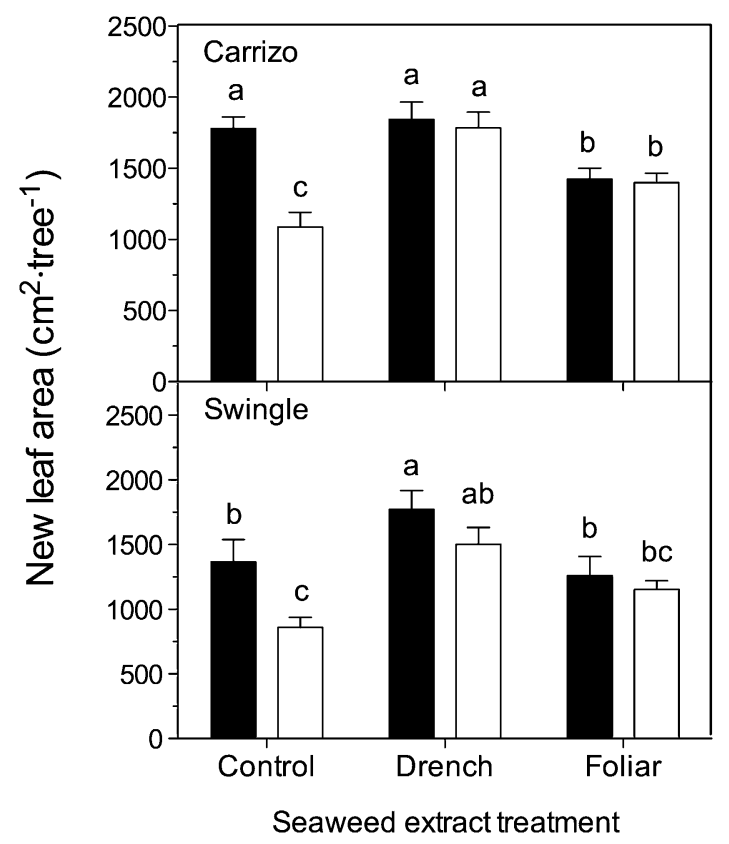

Fig. 2. Total new leaf area produced on 'Hamlin' sweet orange trees grown on 'Carrizo' citrange (A) or 'Swingle' citrumelo $(\mathbf{B})$ rootstocks for 12 weeks under well-watered $(100 \%$ ET $=$ black bars $)$ or drought stress $(50 \% \mathrm{ET}=$ white bars) conditions and treated with seaweed extract as a soil drench or foliar spray compared with untreated control trees. Lowercase letters indicate significant differences among treatments within a rootstock (Tukey's honestly significant difference test, $P=0.05$ ). ET $=$ evapotranspiration.

\section{Carrizo}

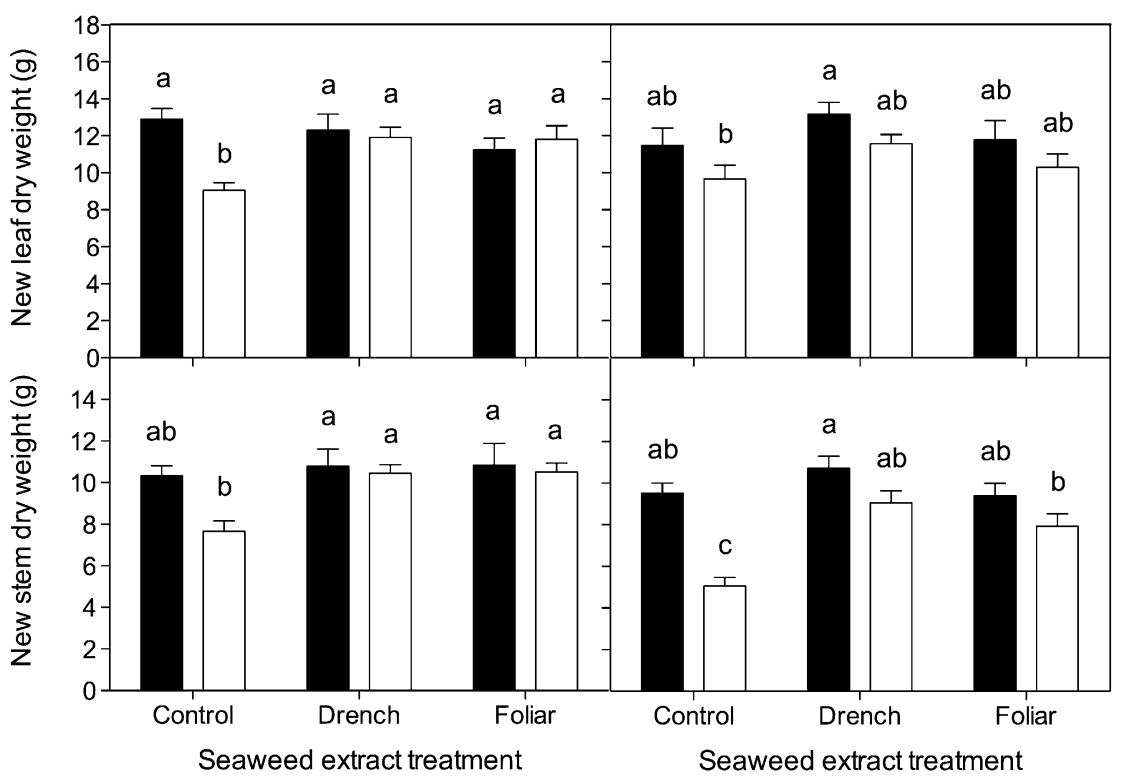

Fig. 3. Dry weight of new leaves and stems of 'Hamlin' sweet orange trees grown on 'Carrizo' citrange (A and $\mathbf{C})$ and 'Swingle' citrumelo $(\mathbf{B}$ and $\mathbf{D})$ rootstocks for 12 weeks under well-watered $(100 \% \mathrm{ET}=$ black bars) or drought stress $(50 \% \mathrm{ET}=$ white bars $)$ conditions and treated with seaweed extract as a soil drench or foliar spray compared with untreated control trees. Lowercase letters indicate significant differences among treatments within a rootstock (Tukey's honestly significant difference test, $P=$ 0.05). ET = evapotranspiration.

control. For trees on 'Swingle' rootstock, SWE treatments maintained new stem dry weight production under drought stress conditions, but there were no significant differences in new leaf dry weight (Figs. 3B and D). There were no significant differences on either rootstock in total aboveground dry weight, root, or total plant dry weights (data not shown). Leaf dry weight/area $\left(\mathrm{mg} \cdot \mathrm{mm}^{-2}\right)$ increased significantly on drought-stressed control trees but did not increase on drought-stressed SWE-treated trees (data not shown).
Root length increased under drought stress conditions on both rootstocks (Fig. 4A-B); however, the SWE drench treatment diminished this response on 'Carrizo' trees. There were no significant differences in root length for foliar-treated 'Carrizo' trees or either treatment on 'Swingle' trees. Root-to-shoot dry weight ratio $(\mathrm{Rt} / \mathrm{St})$ was also greater for droughtstressed control trees compared with wellwatered control trees of both rootstocks (Fig. 4C-D). The SWE treatment diminished the increase in $\mathrm{Rt} / \mathrm{St}$ in response to drought stress.

Net photosynthesis was unaffected by treatment at Week 4 (end of conditioning period) and Week 8 (after 4 weeks of drought stress) (data not shown). However, by Week 12 (after 8 weeks of drought stress), all drought-stressed trees had significantly lower rates of net photosynthesis on both rootstocks compared with well-watered trees regardless of SWE treatment (Fig. 5). There was no significant interaction of water stress $\times$ SWE treatment for stomatal conductance $\left(g_{\mathrm{S}}\right)$, but the main effect of water stress was significant for both rootstocks; therefore, values for $g_{\mathrm{s}}$ were pooled across SWE treatments. For trees grown on 'Carrizo', there was a significant decrease in $g_{\mathrm{s}}$ on drought-stressed tress compared with control trees $\left(0.065 \mathrm{mmol} \mathrm{H} \mathrm{O} \mathrm{m}^{-2} \cdot \mathrm{s}^{-1}\right.$ versus $0.218 \mathrm{mmol} \mathrm{H}_{2} \mathrm{O} \mathrm{m}^{-2} \cdot \mathrm{s}^{-1}, P<0.0001, \mathrm{t}=4.882$, $\mathrm{df}=34$ ). For trees grown on 'Swingle', drought stress had no effect on $g_{\mathrm{s}}$ compared with control trees $\left(0.050 \mathrm{mmol} \mathrm{H}_{2} \mathrm{O} \mathrm{m}^{-2} \cdot \mathrm{s}^{-1}\right.$ versus $0.072 \mathrm{mmol} \mathrm{H}_{2} \mathrm{O} \mathrm{m}^{-2} \cdot \mathrm{s}^{-1}, P=0.0980, \mathrm{t}=1.708$, $\mathrm{df}=30$ ). Leaf WUE (net photosynthesis/ transpiration) was unaffected by drought stress or SWE treatment for trees grown on 'Carrizo' (Fig. 5). However, drought-stressed trees grown on 'Swingle' had lower leaf WUE than control trees (Fig. 5). This reduction in leaf WUE was completely eliminated by the drench SWE treatment and partly eliminated by the foliar SWE treatment for trees grown on 'Swingle'. Whole plant WUE increased in response to drought stress and was unaffected by SWE treatment for trees on 'Carrizo' rootstock (Table 1); however, trees on 'Swingle' had a higher WUE with SWE application compared with drought stress alone.

Similarly, drought-stressed trees had lower $\Psi_{\text {stem }}$ (more stress) on both rootstocks regardless of SWE treatment compared with wellwatered trees both before and after irrigation after 8 weeks of drought stress (Fig. 6). However, within the drought stress treatment, the drench-treated trees on both rootstocks had higher $\Psi_{\text {stem }}$ (less stress) than foliar-treated or untreated drought-stressed trees. A similar pattern was observed at 4 weeks of drought stress (data not shown).

\section{Discussion}

Container-grown trees can be subjected to moisture extremes not experienced by fieldgrown trees because of the limitations in substrate volume and water-holding capacity. Drought stress has been shown to reduce the growth of numerous tree species grown in containers, including eucalyptus (Bachelard, 1986; Myers and Landsberg, 1989), western 
Carrizo

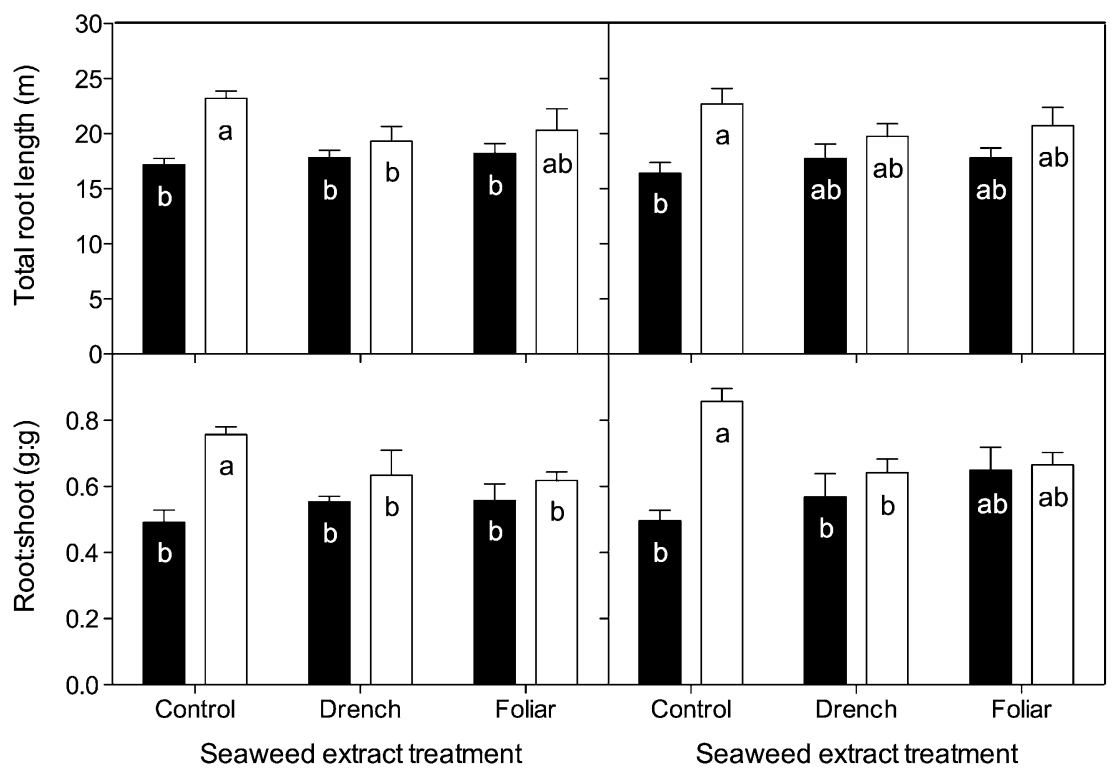

Fig. 4. Total root length and root-to-shoot ratio of 'Hamlin' sweet orange trees grown on 'Carrizo' citrange $(\mathbf{A}$ and $\mathbf{C})$ and 'Swingle' citrumelo (B and D) rootstocks for 8 weeks under well-watered $(100 \%$ ET $=$ black bars) or drought stress $(50 \% \mathrm{ET}=$ white bars) conditions and treated with seaweed extract as a soil drench or foliar spray compared with untreated control trees. Lowercase letters indicate significant differences among treatments within a rootstock (Tukey's honestly significant difference test, $P=0.05)$. ET $=$ evapotranspiration.

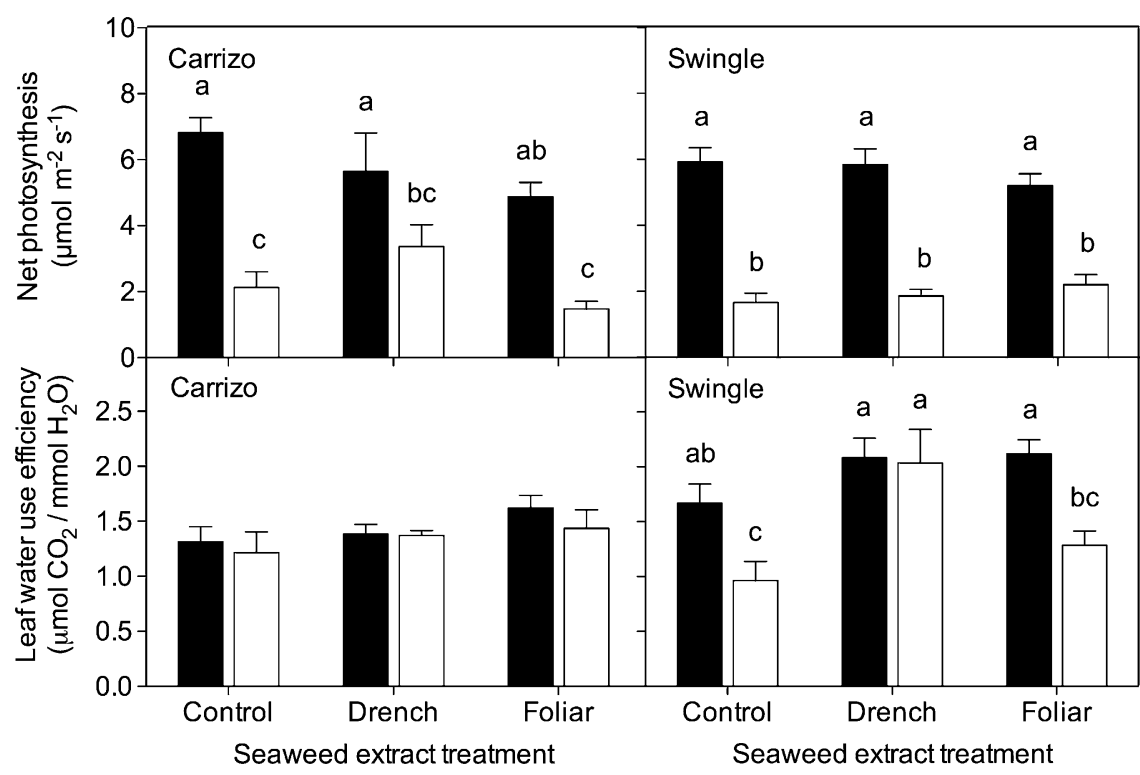

Fig. 5. Net photosynthesis and leaf water use efficiency for 'Hamlin' sweet orange trees grown on 'Carrizo' citrange or 'Swingle' citrumelo rootstocks for 8 weeks under well-watered (100\% ET = black bars) or drought stress $(50 \% \mathrm{ET}=$ white bars $)$ conditions and treated with seaweed extract as a soil drench or foliar spray compared with untreated control trees. Lowercase letters indicate significant differences among treatments within a rootstock (Tukey's honestly significant difference test, $P=0.05$ ). ET $=$ evapotranspiration.

hemlock (O’Reilly et al., 1989), Monterey pine (Kaufmann, 1977), red oak (Larson and Whitmore, 1970), and douglas fir (Haase and Rose, 1995; Rose et al., 1993). Similarly, Cameron et al. (2004) found that the shoot growth of two ornamental woody plant species (Cotinus coggygria and Forsythia Xintermedia) was reduced by $\approx 40 \%$ under $50 \%$ deficit irrigation.
Our study showed that $50 \%$ deficit irrigation reduced the shoot growth of container-grown citrus nursery trees by $\approx 30 \%$ compared with fully irrigated control trees, but SWE treatment mitigated much of this growth reduction.

We found a significant drought-induced reduction in total plant dry weight and a shift in resource allocation from shoot to root growth in response to drought stress. Trees treated with SWE also had a slight reduction in total plant dry weight, but there was no shift in allocation from shoot to root growth. Thus, total shoot growth was maintained under $50 \%$ deficit irrigation. This is similar to results for creeping bentgrass in which SWE-treated plots showed better drought resistance than untreated plots (Zhang and Ervin, 2004). However, in a study on paper birch (Betula papyrifera), a biostimulant containing seaweed extract along with a mix of other components (ascorbate, B vitamins, vitamin E, casein hydrolysate, and humic substances) was found to impart only moderate drought stress tolerance (Richardson et al., 2004). However, the authors indicate that their treatment dosages may have been low for the size plants used.

Photosynthesis was reduced for trees on both rootstocks regardless of SWE treatment, similar to other reports on citrus responses to drought stress (García-Sánchez et al., 2007; Pérez-Pérez et al., 2007). However, the differential response of $g_{\mathrm{s}}$ to drought stress in the two rootstocks suggests that photosynthetic limitation under drought stress may be responsive to different factors in the two rootstocks. 'Swingle', which had no $g_{\mathrm{s}}$ response to drought stress, may have been responding to internal nonstomatal factors that can limit photosynthesis (Farquhar and Sharkey, 1982), whereas trees grown on 'Carrizo', which had reduced $g_{\mathrm{s}}$ in response to drought stress similar to previous reports (García-Sánchez et al., 2007), may have been directly limited by $g_{s}$.

Leaf WUE was unaffected by drought for trees on 'Carrizo' rootstock and, when considered in the context of the net photosynthesis and $g_{\mathrm{s}}$ data, indicates that the reduction in transpirational water loss on 'Carrizo'-grown trees must have been equivalent to the droughtinduced reduction in photosynthesis. This is in contrast, however, to the results for trees grown on 'Swingle' in which leaf WUE declined in response to drought stress, indicating that there was no concomitant decrease in transpiration. Similar to our results for 'Swingle'-grown trees, García-Sánchez et al. (2007) found a significant reduction in leaf WUE for droughtstressed 'Carrizo' seedlings. This discrepancy between our data for 'Carrizo' leaf WUE and that of García-Sánchez et al. (2007) may be the result of our using grafted trees on 'Carrizo' as opposed to 'Carrizo' seedlings. However, it may also be the result of the inherent variability in instantaneous leaf WUE readings, which do not always correspond with longer-term whole plant responses.

Comparative physiological responses of 'Swingle' and 'Carrizo' rootstocks to drought are not well studied and the drought tolerance classification of these two rootstocks is largely based on field observations. In this context and with the data presented, it is notable that SWE application did not increase the whole plant WUE of 'Carrizo' trees above that of drought stress alone, whereas 'Swingle' trees experienced an additional significant increase in whole plant WUE from SWE application above that from drought stress. This may indicate that whole plant WUE was physiologically limited 
Table 1. Whole plant water use efficiency (mg dry weight $/ \mathrm{mL}$ water applied) for 'Hamlin' trees grown on two different rootstocks under well-watered $(100 \% \mathrm{ET})$ or drought stress $(50 \% \mathrm{ET})$ conditions with and without seaweed extract.

\begin{tabular}{lccc}
\hline & & \multicolumn{2}{c}{ Water use efficiency $(\mathrm{mg}$ dry wt $/ \mathrm{mL}$ water) } \\
\cline { 3 - 4 } Irrigation & Rootstock \\
\cline { 3 - 4 } & Seaweed extract & $39.8 \mathrm{~b}^{z}$ & Swingle \\
\hline $100 \%$ ET & None & $66.5 \mathrm{a}$ & $42.8 \mathrm{c}$ \\
$100 \%$ ET & None & $39.0 \mathrm{~b}$ & $59.5 \mathrm{~b}$ \\
$50 \%$ ET & Drench & $63.4 \mathrm{a}$ & $43.1 \mathrm{c}$ \\
$100 \% \mathrm{ET}$ & Drench & $35.3 \mathrm{~b}$ & $69.0 \mathrm{a}$ \\
$50 \%$ ET & Foliar & $66.8 \mathrm{a}$ & $41.0 \mathrm{c}$ \\
\hline
\end{tabular}

zValues within columns with different letters are significantly different $(P=0.05)$ using Tukey's honestly significant difference.

$\mathrm{ET}=$ evapotranspiration .
The biostimulant effects of seaweed extracts are well documented; however, the active compounds responsible for reported effects are only beginning to be elucidated (Khan et al., 2009) and for some SWEs may include cytokinins (Zhang and Ervin, 2004), betaines (MacKinnon et al., 2009) and phenolics (Fan et al., 2011). Cytokinin effects may be the result of the stimulation of production of endogenous cytokinins with application of SWE rather than cytokinins present within the product itself (Khan et al., 2010). Although this was not intended to be an exhaustive study to determine the physiological mechanism(s) of the SWE-induced drought tolerance, some insights were gained. The effects on whole plant WUE, coupled with the differential leaf WUE responses between the two rootstocks and the lack of effects of SWE on photosynthesis, indicate that the observed responses may have been the result of changes in the compounds mentioned or others with known effects on plant water relations.

Seaweed extracts may be a viable approach for maintaining the growth of citrus nursery trees grown in greenhouse conditions under non-uniform irrigation systems. Differences in seaweed species and ecotypes used to make extracts and differences in process technology produce seaweed extracts with different chemical compositions. These results, therefore, may not be transferable to other seaweed extracts (Craigie, 2010; Craigie et al., 2008). Further research should be conducted to better define application rates and timings as well as mode(s) of action.

\section{Literature Cited}

Bachelard, E.P. 1986. Effects of soil moisture stress on the growth of three eucalypt species. II. Growth effects. Aust. For. Res. 16:51-61.

Blunden, G. and S.M. Gordon. 1986. Betaines and their sulphono analogues in marine algae, $\mathrm{p}$. 39-80. In: Roundand, F.E. and D.J. Chapman (eds.). Progress in phycological research. Vol. 4. Biopress Ltd., Bristol, UK.

Bradford, K.J. and T.C. Hsiao. 1982. Physiological responses to moderate water stress, p. 263-324. In: Lange, O.L., P.S. Nobel, C.B. Osmond, and H. Ziegler (eds.). Physiological plant ecology. II: Water relations and carbon assimilation. Springer-Verlag, Berlin, Germany.

Brakke, M. and L.H. Allen. 1995. Gas-exchange of citrus seedlings at different temperatures, vapor-pressure deficits, and soil-water contents. J. Amer. Soc. Hort. Sci. 120:497-504.

Cameron, R.W.F., S. Wilkinson, W.J. Davies, R.S. Harrison-Murray, D. Dunstan, and C. Burgess. 2004. Regulation of plant growth in containergrown ornamentals through the use of controlled irrigation. Acta Hort. 630:305-312.

Castle, W.S., K.D. Bowman, J.H. Graham, and D.P.H. Tucker. 2006. Florida citrus rootstock selection guide-SP 248. University of Florida, Institute of Food and Agricultural Sciences, Cooperative Extension Service, Gainesville, FL.

Craigie, J. 2010. Seaweed extract stimuli in plan science and agriculture. J. Appl. Phycol. doi: 10.1007/s10811-010-9560-4.

Craigie, J., S. MacKinnon, and J. Walter. 2008. Liquid seaweed extracts identified using ${ }^{1} \mathrm{H}$ NMR profiles. J. Appl. Phycol. 20:665-671.

Crouch, I.J., M.T. Smith, J. van Staden, M.J. Lewis, and G.V. Hoad. 1992. Identification of auxins in 'Carrizo' trees and could not be increased above the level already attained by drought stress. However, 'Swingle' trees may not have reached their physiological limit in response to drought stress supporting their classification as relatively drought-sensitive (Castle et al., 2006) and leading to the additional beneficial effects of SWE. This differential response to SWE should be investigated further and perhaps across more rootstock genotypes. 
in a commercial seaweed concentrate. J. Plant Physiol. 139:590-594.

Crouch, I.J. and J. van Staden. 1993. Evidence for the presence of plant growth regulators in commercial seaweed products. Plant Growth Regulat. 13:21-29.

Durand, N., X. Briand, and C. Meyer. 2003. The effect of marine bioactive substances (NPRO) and exogenous cytokinins on nitrate reductase activity in Arabidopsis thaliana. Physiol. Plant. 119:489-493.

Fan, D., D.M. Hodges, J. Zhang, C.W. Kirby, X. Ji, S.J. Locke, A.T. Critchlet, and B. Prithiviraj. 2011. Commercial extract of the brown seaweed Ascophyllum nodosum enhances phenolic antioxidant content of spinach (Spinacia oleracea L.) which protects Caenorhabditis elegans against oxidative and thermal stress. Food Chem. 124:195-202.

Farquhar, G.D. and T.D. Sharkey. 1982. Stomatal conductance and photosynthesis. Annu. Rev. Plant Physiol. 159:317-345.

Florida Department of State. 2010. Rule chapter: 5B62-Citrus nursery stock certification program. 5 Oct. 2010. <https://www.flrules.org/gateway/ ChapterHome.asp?Chapter $=5 \mathrm{~B}-62>$.

Fornes, F., M. Sánchez-Perales, and J.L. Guardiola. 1995. Effect of a seaweed extract on citrus fruit maturation. Acta Hort. 379:75-82.

Fornes, F., M. Sánchez-Perales, and J.L. Guardiola. 2002. Effect of a seaweed extract on the productivity of 'de Nules' Clementine mandarin and navelina orange. Bot. Mar. 45:486-489.

García-Sánchez, F., J.P. Syvertsen, V. Gimeno, P. Botia, and J.G. Perez-Perez. 2007. Responses to flooding and drought stress by two citrus rootstock seedlings with different water-use efficiency. Physiol. Plant. 130:532-542.

Gómez-Cadenas, A., F.R. Tadeo, M. Talon, and E. Primo-Millo. 1996. Leaf abscission induced by ethylene in water stressed intact seedlings of Cleopatra mandarin requires previous abscisic acid accumulation in roots. Plant Physiol. 112:401-408.

Haase, D.L. and R. Rose. 1995. Vector analysis and its use for interpreting plant nutrient shifts in response to silvicultural treatments. For. Sci. 41: 275-294.

Kaufmann, M.R. 1977. Soil temperature and drought effects on growth of Monterey pine. For. Sci. 23:317-325.
Khan, W., U.P. Rayirath, S. Subramanian, M.N. Jithesh, P. Rayorath, D.M. Hodges, A.T. Critchley, J.S. Craige, J. Norrie, and B. Prithiviraj. 2009. Seaweed extracts as biostimulants of plant growth and development. J. Plant Growth Regul. 28:386-399.

Khan, W., D. Hiltz, A. Critchley, and B. Prithiviraj. 2010. Bioassay to detect Ascophyllum nodosum extract-induced cytokinin-like activity in $\mathrm{Arabi}$ dopsis thaliana. J. Appl. Phycol. doi: 10.1007/ s10811-010-9583-x.

Koo, R.C.J. 1988. Response of citrus to seaweedbased nutrient sprays. Proc. Fla. State Hort. Soc. 101:26-28.

Koo, R.C.J. and S. Mayo. 1994. Effects of seaweed sprays on citrus fruit production. Proc. Fla. State Hort. Soc. 107:82-85.

Larson, M.M. and F.W. Whitmore. 1970. Moisture stress affects root regeneration and early growth of red oak seedlings. For. Sci. 16:495498.

MacKinnon, S.L., D. Hiltz, R. Ugarte, and C.A. Craft. 2009. Improved methods of analysis for betaines in Ascophyllum nodosum and its commercial seaweed extracts. J. Appl. Phycol. doi: 10.1007/s10811-009-9483-0.

McCutchan, H. and K.A. Shackel. 1992. Stem water potential as a sensitive indicator of water stress in prune trees (Prunus domestica L. cv. French). J. Amer. Soc. Hort. Sci. 117:607-611.

Myers, B.J. and J.J. Landsberg. 1989. Water stress and seedling growth of two eucalypt species from contrasting habitats. Tree Physiol. 5:207218.

Neily, W., L. Shishkov, S. Nickerson, D. Titus, and J. Norrie. 2010. Commercial extracts from the brown seaweed Ascophyllum nodosum (Acadian ${ }^{\circledR}$ ) improves early establishment and helps resist water stress in vegetable and flower seedlings. HortScience 45:S234

Norrie, J., T. Branson, and P.E. Keathley. 2002. Marine plant extracts impact on grape yield and quality. Acta Hort. 594:315-319.

Ördög, V., W.A. Stirk, J. van Staden, O. Novak, and M. Strand. 2004. Endogenous cytokinins in the three genera of microalgae from the Chlorophyta. J. Physiol. 40:88-95.

O'Reilly, C., J.T. Arnott, and J.N. Owens. 1989. Effects of photoperiod and moisture availability on shoot growth, seedling morphology, and cuticle and epicuticular wax features of container-grown western hemlock seedlings. Can. J. For. Res. 19: 122-131.

Pérez-Pérez, J.G., J.P. Syvertsen, P. Botia, and F. García-Sánchez. 2007. Leaf water relations and net gas exchange responses of salinized Carrizo citrange seedlings during drought stress recovery. Ann. Bot. (Lond.) 100:335-345.

Reitz, S.R. and J.T. Trumble. 1996. Effects of cytokinin-containing seaweed extract on Phaseolus lunatus L.: Influence of nutrient availability and apex removal. Bot. Mar. 39:33-38.

Richardson, A.D., M. Aikens, G.P. Berlyn, and P. Marshall. 2004. Drought stress and paper birch (Betula papyrifera) seedlings: Effects of an organic biostimulant on plant health and stress tolerance, and detection of stress effects with instrument-based, noninvasive methods. J. Arboricult. 30:52-61.

Rose, R., F.G. Gleason, and M. Atkinson. 1993. Morphological and water-stress characteristics of three Douglas-fir stocktypes in relation to seedling performance under different soil moisture conditions. New For. 7:1-17.

Schmidt, R.E. and X. Zhang. 1997. Influence of seaweed on growth and stress tolerance of grasses. Proc. Amer. Forage Grassland Council. 158-162 Ft. Worth, TX; 13-15 Apr. 1997.

Scholander, P.F., H.T. Hammel, E.D. Bradstreet, and E.A. Hemmingsen. 1965. Sap pressure in vascular plants. Science 148:339-346.

Stirk, W.A., M.S. Novak, and J. van Staden. 2003. Cytokinins in macroalgae. Plant Growth Regulat. 41:13-24.

Tennant, D. 1975. A test of a modified line intersect method of estimating root length. J. Ecol. 63:9951001.

Tudela, D. and E. Primo-Millo. 1992. 1-aminocyclopropoane-1-carboxylic acid transported from roots to shoots promotes leaf abscission in Cleopatra mandarin (Citrus reshni Hort. ex Tan) seedlings rehydrated after water stress. Plant Physiol. 100:131-137.

Zhang, X. and E.H. Ervin. 2004. Cytokinincontaining seaweed and humic acid extracts associated with creeping bentgrass leaf cytokinins and drought resistance. Crop Sci. 44: 1737-1745. 